\title{
MAGIA Y POESÍA LÍRICA EN TEÓCRITO Y VIRGILIO
}

\author{
Maria Luisa Acuña \\ Norma Porto de Farias
}

\begin{abstract}
INTRODUCCIÓN
La magia acompana el desarrollo de la vida humana sobre la tierra. Tan mágico le pareció al hombre de las cavernas ver cómo brotaba el fuego por la frotación de dos maderas o por el choque de dos piedras, como el "hacer llover" por la imitación del ruido de la lluvia. En estas dos operaciones el impulsor es el deseo: deseo de obtener fuego para cocer los alimentos o para combatir el frio; deseo de atraer la lluvia sobre la tierra. La magia nace del deseo: cuando el hombre desea algo ardientemente, desarrolla estrategias para alcanzarlo. Cuando en el desarrollo de esas estrategias y mecanismos predominan la imaginación y el sentimiento por encima de la lógica y el raciocinio, surge la acción mágica. El ritual mágico se basa en la fe en el poder del pensamiento, la "omnipotencia del pensamiento", para "ordenar" elementos de la realidad cotidiana en caprichosas combinaciones de fuerte connotación subjetiva, a fin de alcanzar, irracionalmente, deseos que racionalmente son irrealizables. ${ }^{1}$
\end{abstract}

De las múltiples operaciones mágicas posibles interesa aqui la hecha para alcanzar el amor de un hombre o de una mujer desdeñosos; tal es el tema de Tebcrito en su Idillo II $\Phi \alpha \rho \mu \alpha x \varepsilon \cup \tau \rho$ í $\alpha$, Las Magas, y de Virgilio en su Bucólica VIII. La lectura de ambos poemas nos ocupará de aquí en adelante y nos permitira aproximarnos a un hecho de palpitante humanidad, tan antiguo como contemporáneo. El poeta griego y el latino reflejan la ceremonia mágica de su época y arriman, la magia sonora y expresiva de ambas lenguas, griega y latina, para dejarnos dos poemas hechiceros.

\section{EL IDILIO II DE TEÓCRITO}

J.R. Mozzley escribe, en 1901, que la hechicería no está nombrada como tal en textos de autores griegos antiguos antes de finalizar el s.V a.C. Pero al comienzo del s.lII a.C. aparece con toda su fuerza en el Idilio II. Agrega, refiriéndose a la época de Téccrito, que en este periodo la mezcla de religiones sobre la vasta área gobernada por los sucesores de Alejandro, el debilitamiento de cada religión como una fuerza separada y también la debilidad 
de los hombres para obrar fuera de ellas, proveyeron el nido más favorable para el nacimiento de supersticiones irregulares. ${ }^{2}$

Legrand califica al poema de obra maestra de Teocrito, o más bien, una de las obras maestras de la literatura griega, e incluso, una obra maestra de la literatura amorosa universal, y a nuestro entender, no está equivocado. ${ }^{3}$ Se establece su fecha de composición entre los años 265 y 260 a.C. cuando Filino de Cos fue triunfador en la carrera de Olimpia. Técrito debió escribirlo en Cos a su regreso de Alejandría. ${ }^{4}$ Como posible fuente de la Primera

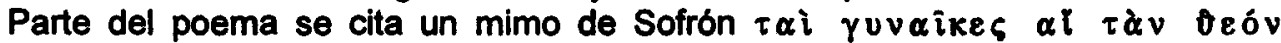
$\varphi \alpha v \tau \imath$ é $\xi \varepsilon \lambda \hat{\alpha} v$. Sólo se conservan algunos fragmentos relacionables con el idilio; pero muy libremente imitados por el siracusano. Legrand echa de menos la poca participación en el diálogo de Testilis; pero reconoce que, confrontando el poema con documentos técnicos, se advierte que Téćcrito conocía el ritual, por eso los actos de Simeta se encadenan, son comprensibles, lo cual corrobora que el cuadro trazado era de gran exactitud para sus contemporáneos. Digamos que la ausencia de diálogo está compensada por la viva gestualidad de ambas mujeres.

La Segunda Parte es el monólogo de Simeta, sentimental, dramático y narrativo; como situación general se asemeja a un monólogo de los siglos III o II a.C. descifrado sobre un papiro y publicado por Grenfell; all, otra mujer engañada, en la puerta del infiel, le reprocha su traición, lo amenaza y le suplica. Este fragmento de Grenfell puede ser una muestra de los mimos líricos que se atribuyen a Simos de Magnesia, conocidos como simodias. Pero, al usar estrofas y estribillo, Teócrito marcó la diferencia e inscribió su composición en el género lírico.

El Idilio II tiene una Introducción (vs. 1 al 16); una Primera Parte (vs. 17 al 63); una Segunda Parte (vs. 64 al 143); un Epilogo (vs. 144 al 162) y una Despedida (vs. 163 al 166).

Empieza directamente con palabras de Simeta a su ayudante Testilis requiriéndole los elementos de la acción mágica a realizar: sus laureles, que tanto pueden ser los que quema en el transcurso del ritual, como las hojas de laurel para masticarlas como hacian las pitonisas a fin de estar inspiradas. Reclama los "filtros" y pide que corone la copa (de los filtros) con lana púrpura. Están en esta introducción nombrados tres elementos de magia amorosa: laureles, filtros y lana púrpura. Simeta declara su intención de encantar al hombre que la atormenta y con su ausencia de doce días la hace sentir abandonada. Saluda a la Luna, Selene, y a la subterránea Hécate, para que haga efectivos sus encantamientos como lo fueron los de Circe, Medea y Perimeda.

La Primera Parte se abre con el verso 17 que es el estribillo:

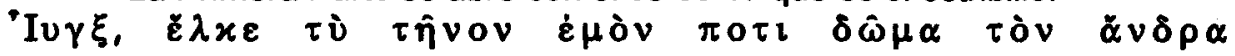


Siguen nueve estrofas, cada una de cuatro versos, separados por el estribillo o refrán, al cual Tebcrito ha potenciado con el orden de las palabras provocando un mutuo enriquecimiento de los niveles semántico, sonoro, ritmico, hasta que se oiga como el conjuro mágico, del cual emana una fuerza envolvente, angustiosa, misteriosa. El hexámetro se abre con el nombre "Iv $\gamma \xi$ traducido Iynx, llamado "torcecuellos" en la versión espafiola, "torcol" en la francesa. La mitologla explica que Iynx o linge, fue hija de Pan y la ninfa Eco; fue transformada en pajaro por Hera, a causa de haber inducido con sus filtros amorosos a Zeus para enamorarse de lo. Sin duda el lynx era un ave de la especie de las lechucitas, ligadas en todo tiempo y lugar a la magia, como el Caburé guarani en nuestra región. En la antigüedad, atado a una rueda, el lynx se utilizaba en magia amorosa.

La etimología de su nombre griego, dice Chantraine, puede venir del verbo iu $\zeta \omega$ que en Homero significa dar gritos para cazar animales, mientras que en Esquilo y Sófocles es "dar gritos de dolor"; la etimología de iu $\zeta \omega$ vendria de una onomatopeya î́ con variantes lov́. î́. $i \alpha \hat{v}$.

En el estribillo el nombre del pajaro en vocativo inicia el verso, seguido del imperativo trae y del pronombre tú y luego el objeto directo a aquél. Las tres palabras forman una cadena de mando triple: la maga ordena al ave obrar el hechizo, él mismo y no otro, tú; la acción del imperativo debe caer sobre

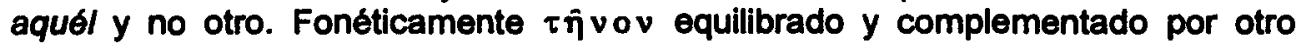
acusativo, $\varepsilon \mu \delta v$, el posesivo mi. Este posesivo referido a Simeta, ocupa el centro del verso, posición que lo vuelve polivalente, va tanto con \&v $\delta \rho \alpha ~ m i$ hombre como con $\delta \hat{\omega} \mu \alpha$ mi casa. El posesivo cierra el primer hemistiquio, los acusativos casa y hombre están en el segundo; son las dos posesiones más amadas por la hechicera, quien está imbuida mientras realiza la ceremonia mágica, del poder de su acción: la posición central de $\dot{\varepsilon} \mu$ òv es la clave del poema: Simeta tiene fe en la omnipotencia de su pensamiento, para la realización de su deseo.

El texto griego de este estribillo, en su aliteración consonántica y su vocalización, deja oir dos voces: la de Simeta y la del ave atada a la rueda mágica. Simeta suena dolorida, agitada, entrecortada, como a tropezones; tal es la distribución de vocales intermedia y cerrada $(\varepsilon$ - o) en el primer hemistiquio, con la cerrada y abierta (o - $\alpha$ ) del segundo hemistiquio; empieza con la angustia, termina abriéndose a la esperanza. Por su parte las consonantes dental $\mathrm{J}$, reiterada tres veces en alternancla con las nasales $v, \mu$, en el primer hemistiquio, marcan el sollozo, la voz entrecortada como el choque de $\tau \pi$. En el segundo hemistiquio está aquietado el llanto, reiteran dentales y nasales $(\tau, \delta, \mu, v)$ que 
con el acompañamiento de la vocal abierta $\alpha$ indican la esperanza que va naciendo en Simeta a medida que avanza el conjuro.

El ritmo envolvente del estribillo resulta de la distribución de las vocales cerradas que sugieren los giros de la rueda donde está atado el lynx, cuyo nombre, abriendo el hexámetro, deja oír su chillido asustado, grito que se prolonga en las vocales medias del primer hemistiquio. Este estribillo reiterado diez veces, separando nueve estrofas de la primera parte, sostiene el clima extraño y estremecedor en que las dos mujeres se mueven.

Ninguna traducción transmite exactamente los contenidos del estribillo. Ninguna traducción transmite la angustia de Simeta, como el texto griego. González Lazo, traductor de la edición de Aguilar, escribe:

Iynx, tú atrae hasta mi casa a aquel, a mi hombre.

E. Legrand traduce en francés:

lynx, attire vers ma demeure cet homme, mon amant

y nuestra interpretación:

Iynx, tú trae a mi casa a aquel, a mi hombre.

En todos los casos se reitera el posesivo que en griego está dicho una sola vez: siempre la concisión inimitable de las lenguas griega y latina.

Continuando con la estructura de la Primera Parte vemos que la primera estrofa indica el primer paso de ritual, esparcir la harina; en la segunda se quema el laurel, y la aliteración del verso es crepitante; en la tercera se funde la cera, o una imagen de cera, y se hace girar el disco de bronce, o thombos o iynx, nombres que también se le dan; en la cuarta estrofa se quema el salvado, Simeta oye el aullido de los perros y ordena a Testilis que haga sonar el bronce. La quinta estrofa marca una pausa en el rito; Simeta advierte a su ayudante del silencio total que las rodea, ¿es que la noche del ritual ha llegado a su climax? ¿Será que ha llegado la alta hora de la noche en que el poder de las tinieblas se acrecienta y los hechizos alcanzan éxito? Recordamos a Apuleyo y sus hechizos en la defensa que debió hacer de sí mismo contra la acusación de magia, y también en sus relatos, cuyas brujerias se cumplen en el silencio de la alta noche, cuando todos 
los seres duermen, cuando toda la naturaleza está en reposo. En ese silencio Simeta lamenta su abandono y el dafío causado por Delfís a su vida.

En la sexta estrofa recomienza la acción, Simeta hace tres libaciones y pronuncia tres veces el mismo deseo: que él olvide a quien ama en ese momento. La séptima estrofa es para quemar el hipomanes que la volverá irresistible para Delfís. Está la imagen de los potros en los montes, enloquecidos por la virtud del hipomanes que hace irresistibles a las yeguas. ${ }^{5}$ La fuerza de la pasión que domina a Simeta le hace olvidar que es humana, hasta sentir y desear como animal en celo. La naturaleza eminentemente fisica del amor que unió a estos dos seres, está evidenciada en esta estrofa, cuyo v. 48 tiene predominio de dáctilos, ritmo acelerado y acompasado por la distribución de la bilabial oclusiva sorda, $\pi$, en altemancia equilibrada con la dental oclusiva sorda $\tau$; las vocales preferentemente acentuadas, $\varepsilon-\alpha$, para obtener el ruido del galope:

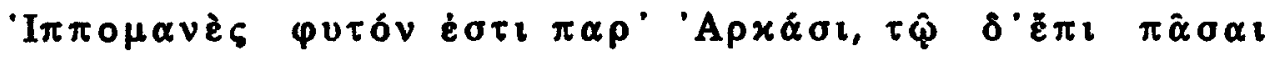

La fricativa $\varphi$ acompañada, estratégicamente, de rato en rato, por la sibilante $\sigma$, hace el roce del aire sobre los cuerpos en carrera. Mientras el v. 49 por su acentuación, vocalización y aliteración consonántica, señala un leve aquietamiento del galope, para destacar un nuevo aceleramiento en el v. 50 :

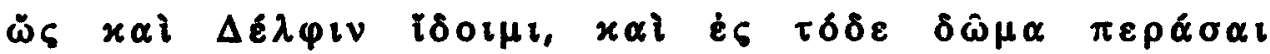

expresivo del máximo deseo de Simeta: " ${ }_{1}$ Cómo quisiera ver a Delfis precipitarse a esta casa..."

idea completada en el v. 51:

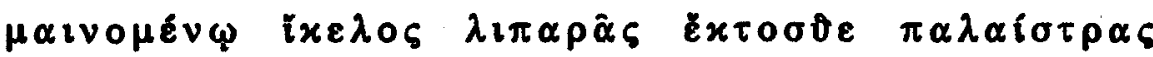

... como un loco, cuando deje la untosa palestra!

$Y$ el estribillo, ya comentado, remata, dando el movimiento de seguimiento enloquecido. En la octava estrofa quema la ropa de Delfis e impreca a Eros que la ha dejado exangue. Quemar la ropa de un ausente, es una acción mágica muy fuerte, porque es desearle un ardor tan intenso que to calcine: nuevamente el estribllo subraya la locura de la acción y de quien la realiza.

La novena estrofa marca la culminación de esta primera parte del ritual: la hechicera machaca un lagarto y ordena a Testilis ir a terminar el hechizo 
en la puerta de Delfis, diciendo los huesos de Delfis amaso. El estribillo rubrica los veloces y vertiginosos giros de la conciencia fuera de sí.

La Segunda Parte, continuación del ritual, contiene el lamento de Simeta y la narración de su historia con Delfis, que ella cuenta a Selene, la Luna, - Diana, Artemis, la diosa de las selvas, de la soledad, la virgen que castigó cruelmente la lujuriosa mirada de Acteón. Es importante recordar estos atributos de la diosa, porque Simeta no está sólo recordando el tiempo feliz de su historia, para después resignarse a perder a su hombre. En realidad está procurando atraer el favor de Selene hacia su causa, que podría ser perdida, porque la diosa invocada es la opuesta a Afrodita, Venus, quien procura el amor, la unión de los seres. La narración de la historia de amor, de su amor, equivale a la narración del mito y sirve para actualizar el tiempo. De este modo Simeta, recuperará el tiempo feliz de su amor con Delfis, mientras Testilis completa el hechizo en la puerta del desdeńoso, para hacerlo "renacer" como hombre enamorado y deseoso de Simeta, como se verá en nuestra interpretación de la operación mágica.

La primera estrofa se inicia con tres preguntas retóricas: desde dónde empezará a llorar su amor, en qué punto empezó, quién la llevó a esta desgracia. Recuerda la venida de la canéfora Anaxó al santuario de Artemis para la procesión en honor de la diosa. Alli se canta por primera vez el segundo estribillo del poema :

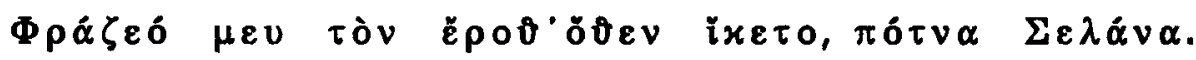

Considera de dónde vino mi amor, sagrada Luna.

Este estribillo se repite doce veces, separando trece estrofas de cinco versos cada una. Difiere algo del primer estribillo en cuanto a sonoridad, ritmo y significado. La vocalización en el primer hemistiquio se inicia con $\alpha$ abierta, clara, que cierra en $\varepsilon \delta$, sigue el diptongo $\varepsilon v$, luego alternando $0, \varepsilon, \omega, 0, \varepsilon$; las consonantes fricativa $\varphi$, la doble $\zeta$, seguida de la nasal $\mu$, una sola dental oclusiva sorda $\tau, y$ dos aspiradas, son menos golpeantes que en el primer estribillo: el sollozo es menos entrecortado, hay un tono entristecido en la voz de la mujer que narra, procurando propiciarse a la Luna, procurando disimular que cedió a la tentación de Venus justamente cuando empezaba la fiesta de Artemis. El segundo hemistiquio tiene vocalización iniciada por $\mathfrak{l}$ aspirada y desarrollada con predominio de a abiertas, por su parte la secuencia de dental, bilabial, dental $\tau, \pi, \tau$, da el sollozo contenido por la seguidilla de nasales y una liquida; el final del hemistiquio permite que la voz se deslice como un suspiro contenido: $\pi$ ó $\tau v \alpha$ $\Sigma \varepsilon \lambda \dot{\alpha} v \alpha$.

La segunda estrofa narra la invitación de Trasa para ir a ver la procesión a la que Simeta concurre muy elegante. La narración atraviesa un tramo peligroso en la tercera estrofa cuando Simeta relata cómo se encontró con Delfis acompañado de Eudamipo, ambos con barbas de un dorado como el rubio 
helicriso y con los pechos más brillantes que la Luna; esta es una buena estrategia de Simeta: los atletas jóvenes eran preferidos por Artemis, si la diosa admira su espléndida juventud ¿cómo podria no comprender a una pobre mujer, enceguecida por su masculina belleza?

La cuarta y quinta estrofas describen los efectos devastadores del amor sobre la joven; ella busca remedios y al fracasar, pide a Testilis que encuentre a Delfis y lo llame de su parte (sexta y parte de la séptima estrofa, que finaliza con la aparición de Delfis). La octava estrofa continúa el tema de la cuarta y quinta, los efectos del amor sobre la enamorada ante el amado. El tratamiento de Teócrito a este tema se ha comparado con el similar de Safo en su Oda 2.

Advirtiendo su confusión, Delfis le dirige palabras del deseo que también él sentía, atribuyendo a Afrodita, Cipris, y a Eros la pasión de Simeta; estas palabras ocupan de la novena a la doceava estrofa. Una vez más está dicho el estribillo. Del v.136 al 141, decimotercera estrofa, se completa el relato de aquel primer encuentro; los v.142 y 143 van como cierre del estribillo con la excusa de no cansar a la Luna con abundancia de detalles: pudor de Simeta y natural templanza de la poesía griega, siempre en ejercicio de un ne quid nimis saludable para la perdurabilidad de sus textos. Sigue el Epílogo, de vs.144 a 162 , con el final del relato, la traición, el dolor de Simeta y su amenaza de llevar al ingrato a la puerta del Hades, si persiste en su crueldad.

La Despedida, de vs. 163 a 166, contiene el saludo a la Luna y a las estrellas que escoltan el carro de la Noche. Técrito nos advierte, con esta poética despedida, que la hechicera habia detenido el tiempo con su magia ritual, ahora libera a la Noche, a la Luna, al tiempo, para que sigan su curso natural. Parar el sol, detener la luna, son prodigios que la magia obra, en el decir de los griegos y latinos; también Apuleyo nos amonesta a ser menos incrédulos con los prodigios que pueden obrarse con la magia.

Vamos ahora a intentar una interpretación del significado de este rito. Iynx o linge, por su desmesura al hechizar con sus filtros a Zeus, transformada en ave, debe expiar su culpa atada a una rueda, como los condenados al suplicio de la rueda en el Hades. Quienes practican magia amorosa reiteran su suplicio una y otra vez, confiando en que realizará lo que se le pida. Simeta descansa en el poder del lynx; pero también en los elementos y acciones que combina en el transcurso de la ceremonia.

Los números mencionados en el poema son importantes: el 3, el 9 múltiplo de 3. También el 13, porque Simeta espera 12 dias de ausencia de Delfis, para encantario en el día décimotercero. La triple invocación y libación en honor de Hécate, para obtener su favor en aire, mar y tierra, además del mundo subterráneo. ${ }^{6}$ En la primera parte se describe la ceremonia mágica en 9 estrofas que son los 9 pasos de la acción. El 9 es el múltiplo de 3; aquí recuerda los 9 
meses de la concepción del niño; los 9 pasos del hechizo indican una cuenta regresiva de 9 a 1 , en cuyo transcurso Delfis, ingrato y olvidadizo, es desmembrado, esparcido, consumido por el fuego; pero no para siempre, porque Testilis debe llevar las thróna y amasarlas en el umbral de la casa del joven, seguramente formando una figura humana a la cual dará vida al escupir sobre ella, a fin de que un nuevo Delfis, simbolicamente muerto y simbólicamente renacido, lleno de deseo, regrese a Simeta.

Pero para el éxito de esta operación, debe cumplirse una condición indispensable: el momento de este "renacer" debe coincidir con el momento en que se mostró más enamorado de Simeta. Para ello la maga empieza a narrar la historia de su amor a Selene, empleando trece secuencias, en trece estrofas, número lunar, puesto que el mes lunar tiene 26 dlas, 13 es la mitad de ese lapso; precisamente la narración llega en la estrofa trece al momento del primer encuentro amoroso entre Delfis y su enamorada; instante que debe coincidir con la operación de Testilis. Asi, por la narración, se recupera el tiempo anterior, lo pasado se hace presente, y en ese presente, se logra un amante "renacido" y lleno de amor nuevamente.

A pesar de los referentes literarios citados al comienzo, que bien pueden haber contribuido a la belleza formal del Idilio II, pensamos que Técrito nos ha dejado un testimonio, recogido de un relato oral conocido en su época, que personalmente lo impresionó, conmovió e inspiro. Al tema mágico se añade el lenguaje, la lengua poética de Técrito, que podria ser objeto de un estudio más exhaustivo que las pocas notas indicadas en esta ocasión. Pero sin duda Legrand no se equivocó al nombrar al Idillo || como una obra maestra de la literatura amorosa griega, por su calidad poética, por su humanidad, por su actualidad intemporal como conflicto del ser humano.

\section{LA BUCÓLICA VIII DE VIRGILIO}

Virgilio imita el encantamiento amoroso del Idllio II de Teccrito en la segunda parte de su Bucólica VIII, a pedido quizás de Polión, como se desprende de los versos 11 y 12 de la misma obra ${ }^{7}$. La expresión de sentimientos es más contenida y mesurada en la composición del poeta latino que en la de su modelo, lo que ha llevado a algunos comentaristas a valoraria inferior al Idilio de Técrito" , opinión que no compartimos ya que se logra el mismo clima de encanto poético con un menor desarrollo.

La Bucólica engarza el contrapunto de dos pastores, Damón y Alfesibeo, introducido por un exordlo. Los cantos, de estructura simétrica, se unen por paralelismo y oposición temáticos: ambos pastores aluden a penas de un amor no correspondido, pero la actitud de los amantes es diferente. Damón se queja y maldice por el desamor de la pastora Nisa que se casa con otro, pero es incapaz de actuar; su sufrimiento lo obnubila, lo paraliza hasta el punto que la 
única salida posible es el suicidio. En el canto de Alfesibeo, la pastora, traicionada por su amante, también sufre, pero no se conforma con el lamento, trata de atraerlo con artes mágicas que cumplen con su cometido porque el amado regresa. Nuestro interés se centrará en el canto de Alfesibeo (versos 64-109) que reproduce el ritual de magia amatoria.

Virgilio toma de Técrito muchos de los elementos formales. Desaparece en su Bucólica lo que corresponde a la segunda parte del Idilio, el canto de Simeta a Selene. Estructuralmente mantiene la forma de estrofas separadas por un estribillo, ya que su ritmo reiterativo conviene a la fórmula de encantamiento y a la expresión lírica. Los rasgos diversos del ritual en uno y otro poeta marcan posiblemente una diferencia no sólo de tratamiento literario sino real en la práctica de magia amorosa. Virgilio probablemente haya descripto una ceremonia realizada por sus contemporáneos y coterráneos conocida por él; así lo indica C. Bailey. ${ }^{9}$ El agua lustral, la fuerza de las ataduras de los nudos, y, sobre todo, el traslado del hechizo a la fórmula, a los conjuros, reconocen una raiz italiana.

Los cinco versos iniciales de la composición preludian el clima de encantamiento poético a través de la potestad del canto que domina la naturaleza; caracteristica del género bucólico. La conmoción es total, todo el mundo natural se inmoviliza maravillado por la canción: la novilla admirada se olvida de su pastoreo Immemor herbarum est mirata iuuenca, los linces quedan estupefactos stupefactae lynces, y los ríos detienen su curso desafiando el poder natural de su cauce mutata suos requierunt flumina cursus. Tres versos $-2,3$ y 4- en gradación ascendente, est mirata, stupefactae, requlerunt, admiración, estupefacción y quietud total, están enmarcados por los versos 1 y 5 , las musas de los Pastores, que abren y cierran un circulo de perfección atemporal por el sortilegio del canto: 


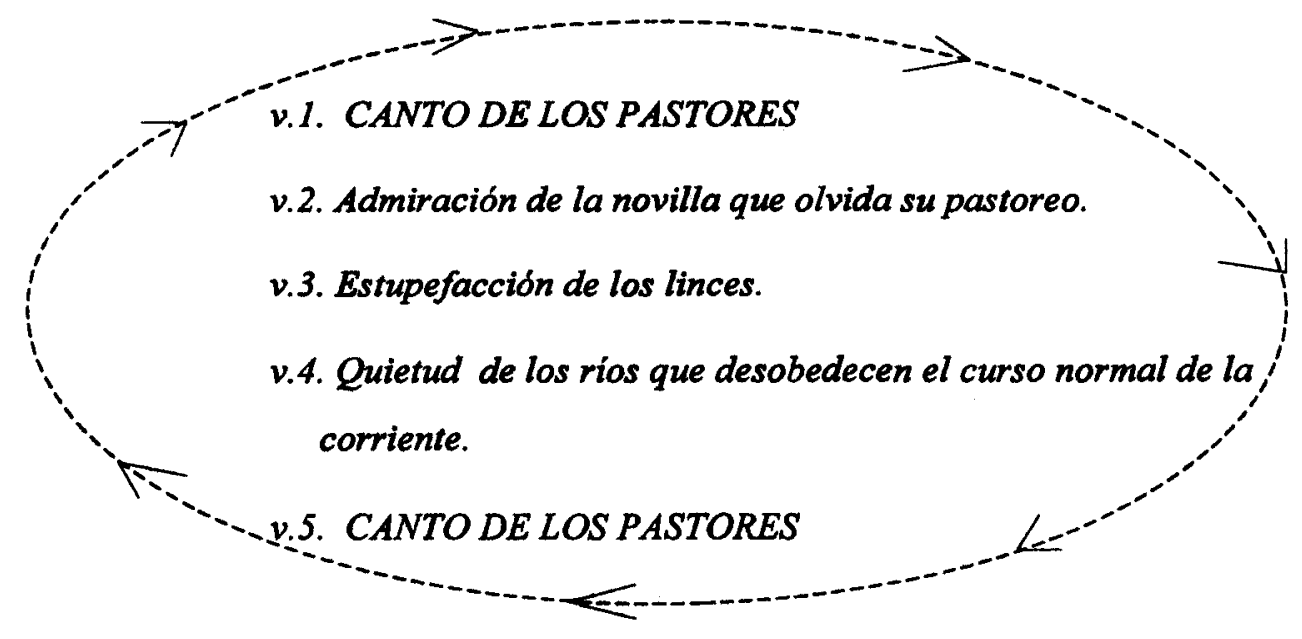

Los versos 62 y 63 sirven de enlace a la canción de ambos pastores; el final trágico de Damón, suicida por amor, y la invocación a las Piérides, las Musas, que inspirarán el canto de Alfesibeo, o mejor hablarán por é. La invocación a las Musas en este lugar no es casual. Si bien es un locus poético, posee aqul todo el significado primigenio de convalidar con su palabra la realidad absoluta, el obrar pleno, y de este modo garantizar con el mito la eficacia de la ceremonia, una manera de reforzar la fórmula mágica con el mito ${ }^{10}$. La reiteración de la palabra carmen canto, encantamiento, cuatro veces al comienzo de la segunda parte, más las diez veces que este vocablo se repite en el estribillo, tiene como referente mítico y poético a las Musas de la invocación.

Como en Téccrito, la acción mágica es realizada por dos mujeres, la enamorada y su ayudante; sin embargo el ambiente urbano del Idillo II se transforma en pastoril en la Bucblica Vill. El amante traidor es, en el poeta alejandrino, un atleta, participe como su enamorada Simeta de unas fiestas ciudadanas. En el poeta latino, el perjuro es un pastor que sugerentemente tiene el nombre de Dafnis, el mismo de aquel mítico Dafnis, considerado padre de la pastoral, querido por todas las mujeres e infiel a su ninfa amada por el ardid engañoso de otra mujer. Aunque con rasgos tipicamente romanos, la ceremonia, pasada por el tamiz del lenguaje poético, conserva aspectos de la magia amorosa realizada en todo tiempo y lugar, y que, como se inserta en el drama cotidiano de la vida, sirve de motivo recurrente a la literatura. 
Una pastora, angustiada por el desamor de Dafnis, consigue por medio de artes mágicas recuperar a su pastor. El encantamiento, realizado per modum Impetrationis, se cumple a través de la potencia de las palabras y ademanes rituales. Las acciones, los objetos, la fórmula, el mito y la tradición mágicos están desarrollados 0 , a veces, tan sólo sugeridos por un clima creado por sonidos e imágenes.

La Bucólica tiene estructura dramática, las magas se desplazan en torno a un altar donde ejecutan diversas operaciones. El estilo directo nos permite escuchar los mandatos de la Pastora: trae agua effer aquam, cine estos altares con suave cinta molli cinge haec altaria ultta, e imaginar los movimientos de Amaryllis, su compañera. Son dos personajes que actúan en un escenario. El lirismo está dado por el tratamiento del lenguaje reforzado por el estribillo. Este se asemeja en construcción, connotación, ritmo y función al de Técrito. Pero el mínimo cambio introducido marca la diferencia que existe en esencia entre las composiciones de ambos poetas.

Ducite ab urbe domún, mea cármina, dúcite Daphnim . Traed de la ciudad a casa, conjuros mías, traed a Dafin's.

Ha desaparecido el ave hechicera, el lynx. El poder de la magia se confiere y se condensa en el vocativo, mea carmina, conjuros míos, colocado en medio del verso. Carmina tiene la acepción originaria de canto, canción. Por ampliación semántica, pasa a ser también la composición sujeta a medida y ritmo como la poesia o las fórmulas de encantamiento, los conjuros. El trasladar el poder del hechizo del objeto (el ave) a la fórmula o la palabra rítmica se corresponde con la invocación inicial a la Piérides, las Musas; y al afán de conseguir la comunicación con un orden atemporal y metahistórico. Se relaciona además con la introducción de la composición total, ya comentada, donde el canto de los pastores Damón y Alfesibeo maravillan a todo el mundo natural y donde la palabra musa está utilizada como sustantivo común significando canto Pastorum musam Damonis et Alphesiboei, el canto de los pastores Damón y Alfesibeo.

El atributo de concentración se logra por ese sistema de correspondencias y por la estructura formal y ritmica del verso. El vocativo, mea carmina, de mayor intensidad significativa, está colocado en el centro, y de alli se irradia al primero y segundo tramo del verso, simétricos entre sí. El posesivo mea, como en Técrito, es polivalente. Por su morfología modifica a carmina, pero por su posición se expande también a domun, mi casa.

Dacite ab arbe domun dakltab urbe domam mea carmina

dúcite Daphnim dakite dafnim 
El efecto sonoro, inicial y final de verso, es el mismo; dúkitab-dúcitedáf. En ambos casos la sucesión de consonantes y vocales se mueve de una posición anterior (d/dental), retraída violentamente a una posterior (u/gutural) y de alli avanza paulatinamente, marcada por los golpeteos de las oclusivas (k-t-b) a posiciones anteriores: gutural, dental, labial. Las vocales siguen el mismo efecto además de abrirse. La sensación de percusión y marcha dificultosa se acentúa con las silabas trabadas, tab - daf; se aquietan y suavizan al final de cada tramo y en el vocativo con las aliteraciones nasales: domúm, mea cármina, Dáphnim.

Este ritmo de inquietud y obstáculos que se serena, vuelve a agitarse y a apaciguarse, señalan, por una parte, la conmoción de la pastora abandonada, la alteración de un orden dado, la perturbación del momento de la ceremonia; y por otro, la confianza en el poder restaurador del orden y de las pasiones puestas en el acto mágico.

Si trazáramos el esquema del verso, nuevamente el movimiento sería circular. El punto de partida y de llegada sería la exhortación de hacer volver a su casa a Dafnis, y el centro motor, que genera el movimiento, estaría dado por los encantamientos:

Ducite ab urbe domum

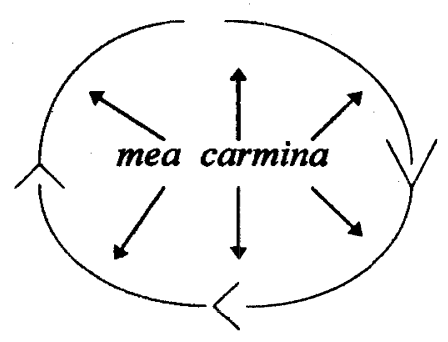

Ducite Daphnim

El círculo se cierra dejando un centro donde es posible reordenar el caos, que, desde la perspectiva de la pastora, significa la pérdida del amante. Virgilio sabe amoldar la música, el ritmo, los efectos sonoros del verso, al tema que desarrolla. 
Después de los versos introductorios, en el 64, el cuadro se abre abruptamente con una escena en movimiento. Dos versos son suficientes para colmar el aire de sensaciones aromáticas que crean el ambiente propicio para el hechizo:

\section{uerbenasque adole pinguis et mascula tura quema verbenas pinglies e incienso macho}

La imagen olfativa de hierbas perfumadas acrecienta su valor con la utilización del verbo adoleo, en cuya raíz está el verbo oleo, oler, intensificado por el prefijo ad, oler mucho, y que especificamente significa quemar perfumes para un sacrificio.

La acción, que corresponde al ritual, se alterna con el canto, o bien explicativo del fin de la ceremonia, o bien referido a un hecho mítico o aceptado tradicionalmente como mágico, que avala la actuación. Así en la primera estrofa, dos versos están destinados a la acción: traer agua, cenir el altar con suave cinta, quemar verbenas $e$ incienso macho. Todo esto no tiene valor sin la presencia de la palabra, del canto, lo que corresponde a la fórmula mágica garantida por el mito o la tradición: nihil hic nisi carmina desunt, aqui no falte nada sino los encantamientos. Esta alternancia se observa hasta el final de la composición.

El hechizo, siguiendo a Teócrito, se realiza en la sucesión de nueve estrofas. En Virgilio hay una décima y última que resume el desenlace: e regreso de Dafnis. En la primera estrofa, ya analizada anteriormente, se sefiala la escenografla y se produce el ámbito propicio: en medio de una agitación febril de las protagonistas, de órdenes que se suceden en un rápido encadenamiento, indicios del estado de ánimo de las celebrantes, la atmósfera se llena de aromas alrededor de un altar rodeado de cintas donde arde el fuego. El primer mandato es el de traer agua. Agua y fuego, dos elementos sustanciales en un ritual mágico o religioso por sus efectos purificadores capaces de revertir una situación considerada transgresora de un orden ya sea macro o microcosmico, capaces de hacer renacer un mundo u hombre nuevos. Sigue la explicación del propósito, transformar los sentimientos del amante y atraerlo con artes mágicas, para concluir con una aseveración, nada se consigue sin los carmina, los conjuros. Continúa entonces la impetración dada en el estribillo, "Traed de la ciudad a casa, conjuros mios, traed a Dafnis", con el que comienza el hechizo propiamente dicho: y el aire se llena de sonidos, de ruegos en los que se deposita la confianza de que sus deseos se cumplan. Tal como lo reafirman los tres versos siguientes de la segunda estrofa. Tres versos que redoblan el ritmo de rogativa oral y del poder del canto en tres espacios: cielo, tierra y mundo subterráneo. Cada verso en los que se repite la palabra: carmina, caminibus, cantando, corresponde a un ámbito especifico: Los cantos pueden hacer bajar del cielo a la luna (cielo); con cantos Circe transformó a los companeros de Ulises (tierra); en los prados cantando se 
quiebra la fría serpiente (mundo subterráneo, si consideramos que la serpiente es un animal ctónico). ${ }^{11}$

Los encantamientos ponen en marcha el engranaje de la ceremonia y el estribillo reiterado sirve de cuh́a donde se apoya cada movimiento. De ese modo los conjuros crean un movimiento con dos fuentes de generación, una desde el interior, el centro del estribillo; y otra desde afuera, cada vez que se repite el mismo.

En las dos estrofas siguientes, tercera y cuarta, presenciamos actos de magia homeopática, tal como la designa J.Frazer, pues se considera como agente motor la semejanza entre la práctica realizada y el hecho deseado. Las magas tienen una effigles, posiblemente una estatuilla de Dafnis a la que atrapan en una urdimbre de tres hilos de tres colores tres veces, figurando los lazos afectivos y el abrazo amoroso. Llevan esta imagen tres veces alrededor del altar, atan con tres nudos cada uno de los tres colores, nueve en total. Las acciones son realizadas a veces por la pastora (estrofa tercera), a veces por Amaryllis (estrofa cuarta), lo que muestra a ambas activas, imbuidas de su accionar. Al final de cada estrofa se presenta la explicación y la manifestación de la fórmula. Numero deus impare gaudet, la divinidad se regocija con el número impar, Veneris, dic, uincula necto, di ato los vínculos de Venus. La divinidad, a la que el poema hace alusión, es Hécate, nombrada expresamente por las magas de Teócrito; es la diosa de la hechicería. ${ }^{12}$ La simbología del número tres y su múltiplo nueve, que sugieren un estado perfecto, la unión de la dualidad, ya fueron comentados en el análisis del Idilio II. Los números impares que agradan a la divinidad son simbólicamente considerados como números afirmativos, activos. La recurrencia del tres permanece en las narraciones folklóricas europeas, tres hermanos ejecutan sucesivamente las mismas acciones, concesión de tres objetos mágicos, enunciado de tres deseos, etc. En la Bucólica, el símbolo del nueve, nueve hilos en la urdimbre de los tejidos, nueve nudos, nueve estrofas para la realización del ritual, se liga con la invocación inicial a las Musas que también son nueve.

necte tribus nodis ternos, Amaryill, colores

necte, Amaryill, modo et, Veneris dic "uíncula necto".

Ata, Amaryllis, con tres nudos, cada uno de los tres colores, ata Amaryllis de tal manera y di: "Ato los lazos de Venus".

De los variados verbos que en latín expresan ligar, entrelazar, atar, Virgilio elige necto, anudar, porque es el que más conviene por su sonoridad a la imagen sugerente de ligazón indestructible, de traba que impide la separación de los amantes. La anáfora inicial de versos nécte - nécte y el final nécto conforman por su posición, comienzo y fin, y por su aliteración de oclusivas necte, necte, dic, necto, semánticamente reforzado por nodis con nudos, y uincula vinculos, una ligadura, una trabazón irrompible cual el deseo de la 
Pastora de unirse en cuerpo y alma a su amado. La fórmula "Veneris" dic "uincula nécto", ato los lazos de Venus, vuelve a tener valor absoluto por su significado, por ser la conclusión de la acción y por insinuar a través de las aliteraciones dos sensaciones de la relacion amorosa: la dulzura apacible de las fricativas, uen - uin (Veneris-uíncula) y la fortaleza de la unión, ya comentada, dic - necto. Toda esta carga de significantes se resumen en dos versos. Por una parte, la magia imitativa; por otra, el sortilegio de la poesía virgiliana. El sentido mágico de atadura que posee el nudo es una prueba más de que Virgilio describe una ceremonia italiana conocida por el. En el ritual estatal, el Flamen Dialis no podia llevar nudos en su vestidura pues debia ser ceremonialmente libre.

Hasta aqui la primera parte de la celebración que culmina en la ligadura indestructible. Preparación, primera estrofa; ensalmos, segunda estrofa; actuación, tercera y cuarta estrofas.

La quinta estrofa, mitad de la estructura y climax dramático, describe los efectos de la pasión comparable a la acción del fuego que endurece el barro y derrite la cera, mientras continúa la ceremonia, quemar el trigo y el laurel. La utilización de verbos incoativos, durescit, llquescit, endurecerse, licuarse; además de su sonoridad sirven para expresar una acción que recién comienza, pero en la que se confia continúe hasta lograr su eficacia. Esta estrofa central está contaminada totalmente por el fuego. En cada verso una imagen: Igni, con el fuego; incende, enciende; urit, abrasa; cadena acumulativa que se resuelve con el deseo vehemente de que ambos amantes ardan en fuego amoroso imitando a las llamas que en ese momento están fraguando una estatuilla de barro, están derritiendo otra efigie de cera y quemando el laurel con brea. Virgilio nos habla del barro y la cera que están sobre el altar expuestos a las llamas. Quizá con estos elementos se hayan construido dos estatuillas figurativas del Pastor. El laurel también reproduce a Dafnis cuyo nombre está ligado en la mitología con el laurel. ${ }^{13}$ En Teócrito se nombra sólo una estatuilla, la de cera. En la Bucólica hay además una de barro. Servio, comentarlsta de Virgilio, ensaya dos posibles explicaciones: una, que la imagen de barro es la de la Pastora que se endurece, y la de cera, es de su amante que se derrite. La otra explicación es que las dos estatuillas son del amante infiel que se endurece en relación a otras mujeres y se derrite en relación a la protagonista. C. Bailey adhiere a la segunda interpretación. ${ }^{14}$ Nosotros, sin desechar la opinión de Bailey, consideramos que la imagen de cera que se funde representa el Pastor derretido de amor, pero también a la destrucción ceremonial del amante. La estatuilla de barro que se consolida es la imagen del hombre nuevo enamorado que está renaciendo. Los efectos de la atadura de los lazos de Venus se hacen patentes.

La estrofa sexta amplía el deseo impetuoso de que Dafnis fuera arrebatado por un amor fogoso como el de un animal joven en celo. Los potros y yeguas de Tebcrito son aqul una temera y un novillo. La fuerza del instinto y sus efectos son descriptos con mayor detenimiento que en el poeta alejandrino. Una bella imagen de la ternera que, exhausta de tanto recorrer los bosques en busca 
de su novillo, olvidada del tiempo ya que deja avanzar la noche sin retirarse del monte, yace tendida junto al rio sobre la gramilla, totalmente perdidos los sentidos por amor. Después de esta hermosa comparación poética, que sirve de sosiego, anticlimax y liberación de los sentimientos, continúan tres estrofas que corresponden a tres momentos del ritual, el último inconcluso.

Las dos estrofas siguientes comienzan con la mención de dos elementos que serán procesados en la ceremonia: has exuulas, estos despojos; y has herbas atque haec uenena, estas hierbas y estos venenos. Las prendas son depositadas en el suelo junto al umbral, alli donde la celebrante quiere ver aparecer nuevamente la figura de Dafnis. Actúa aqui el principio de la parte en relación al todo. Sus prendas confiadas a la tierra, concretamente la del umbral de la casa, podrán atraer al amante. El umbral es un símbolo de transición de un estado a otro, en este caso es el paso del desprecio al amor. Se manipulan hierbas y venenos traídos de un lugar exótico. Sus poderes mágicos están atestiguados por la tradición ya que su eficacia se confirma al haber sido utilizados por un tercer hechicero en metamorfosis, en agitar seres de ultratumba o en modificar el ciclo natural: Con éstos (hierbas y venenos) vi yo a Meris ya convertirse en lobo y esconderse en las selvas, ya sacar las ánimas de los profundos sepulcros y trasladar a otros sitios las mieses ya crecidas. Otra nota tipicamente romana, atraer la cosecha ajena por medio de conjuros. La Ley de las XII Tablas prohibe expresamente esta práctica. ${ }^{15}$

La última parte del ritual descripta en la novena estrofa no se cumple, arrojar las cenizas hacia atrás a la corriente de un arroyo y no volverse para mirar. El encantamiento de tirar objetos hacia atrás sin darse vuelta, o simplemente el hechizo de una acción realizada sin volver la cabeza está registrado desde épocas muy antiguas en la tradición bíblica y literaria grecolatina, sirvan como ejemplos la mujer de Lot, Deucalión y Pirra, Orfeo y Eurídice. Existe aún en la actualidad en nuestro medio. Una versión recogida entre los habitantes del Chaco cuenta que las verrugas desaparecen si se arrojan granos de sal al fuego sin darse vuelta a mirarlas.

La décima estrofa delinea el desenlace de una práctica mágica que ha obtenido resultados favorables. Dos indicios sugieren un augurio propicio: repentinamente las cenizas que deberian ser tiradas comienzan a arder y el perro Hylax ladra en el umbral. El ladrido del perro anunciando la venida de un visitante enmarca una escena campesina. Las celebrantes no se atreven todavla a creer plenamente. En su ansiedad piensan que sus ardientes deseos las hacen soriar. Pero el estribillo final, que mantiene la estructura de los anteriores, con leves diferencias, confirma el regreso de Dafnis: “Cesad, conjuros, cesad, de la ciudad ya viene Dafnis". De las cenizas que se han formado al quemar la estatuilla y el laurel que representan a Dafnis y su muerte celebratoria, se enciende espontáneamente el fuego: el pastor, un nuevo hombre enamorado, renacido de las cenizas, regresa a su amante. 
La magia ha obrado en el plano de la realidad representada, pero también en el plano de la creación literaria ya que imágenes, sonidos, conjuros, símbolos, correspondencias, bellamente engarzados, producen un efecto de verdadero hechizo poético. En tiempos de Virgilio se intentaba separar magia de religión, aunque no se lograra cabalmente hacerto, puesto que muchas ceremonias religiosas tenian su fuerte acento mágico, como la que el poeta describe en el libro VI de la Enelda, el sacrificio realizado por Eneas con la Sibila antes de iniciar el descenso a los infiernos. La Bucólica VIII pudo nacer como respuesta a un pedido de Polión; pero en su desarrollo la libertad interior, la sensibilidad de Virgilio y su conocimiento indudable de operaciones similares, comunes en su época, transmutaron, engalanaron y crearon un poema mágico.

\section{NOTAS}

${ }^{1}$ Vid. Emesto de Martino, Magia y Civilización, El Ateneo, Bs. As., 1965.

${ }^{2}$ J.R.Mozzley en Dictionary of Greek \& Roman Antiquities, Third edition, Vol. II, London 1901, art. SUPERSTITIO.

${ }^{3}$ En Bucoliques Grecs, tome I, Théocrite, texte établi et traduit par Ph.E.Legrand, Ve. edition, Paris, Les Belles Lettres, 1960; dice Legrand en su introducción al Idilio II,

“ L'idylle II est donc une oeuvre de la maturité de Théocrite. C'est, a mon avise, son chef-d'oeuvre. J'ajoute: un des chefs-d'oeuvre de la poésie grecque. Je dirais volentiers: un chef-d'oeuvre de la littérature d'amour universelle".

${ }^{4}$ Vid. Legrand en op.cit. 
${ }^{5}$ Se llama hipomanes, en realidad, no a una planta, sino a una secreción de las yeguas en celo, por eso, en su Diccionario, Chantraine pone entre signos de interrogación el uso que hace Teócrito de este término en el verso 48 del Idilio II.

${ }^{6}$ Hécate, diosa de los encantamientos, inventora de la hechicería, su estatua se representaba con triple cuerpo o tricéfala en las encrucijadas. Se la relacionó con el mundo de las sombras, si bien en época muy antigua se la consideraba independiente de los olímpicos, con prerrogativas en todos los dominios, para favorecer a todos los hombres con bienes que mejorasen su vida (ganado, pesca, prosperidad material) y su estado social (elocuencia en asambleas, victoria en juegos y batallas). Fue invocada como diosa nutricia de la juventud con igual título que Artemis y Apolo. En la 4ta estrofa de la primera parte del Idilio II, Simeta identifica a Artemis con Hécate, testimoniando así que ambas diosas tenian funciones y nombres, junto con el de Selene, la Luna, intercambiables.

${ }^{7}$ At te principium; tibi desinet: accipe iussis / carmina coepta tuis.

Tú eres el principio; para ti el final, acepta este poema iniciado por tus mandatos.

${ }^{8}$ Es la opinión de E. de Saint-Denis en su estudio preliminar a la versión bilingtie latín - francés de las Bucólicas de Virgilio. Paris, Les Belles Lettres, 1963, p.58.

${ }^{9}$ Bailey, C., Religion in Virgil, Oxford, Clarendon Press, 1935, Cap. I.

${ }^{10}$ Para el simbolismo y sentido mítico de las Musas, ver W. F. Otto, Las Musas. El origen divino del canto y del mito. Traducción, introducción y notas de Hugo Bauzá, Bs.As., EUDEBA, 1981. Otto sefiala que el canto de las Musas posee el valor de una revelación. "El canto y la palabra tienen un significado como sólo la verdadera divinidad puede tenerlo: es la manifestación del ser de las casas; es la manifestación de la naturaleza tal que sin el canto no se plenifica la obra de creación y el mundo no estaría completo." P.109.

${ }^{11}$ La serpiente es un símbolo multivalente, uno de ellos es la fuerza vital del mundo subterráneo. En este caso también puede considerarse símbolo del mal. 
12 Ver nota 6.

${ }^{13}$ Dafnis, el semidiós siciliano, habia nacido en un bosque de laureles, de ahí su nombre.

${ }^{14}$ Bailey, op. cit.

${ }^{15}$ Ley de las XII Tablas: Neue alienam segestem pellexeris, no atraigas la cosecha ajena con conjuros. 